\title{
Synthesis of biodiesel in capillary microreactors
}

\author{
Juan Sun, Jingxi Ju, Lei Ji, Lixiong Zhang*, Nanping Xu
}

State Key Laboratory of Materials-Oriented Chemical Engineering and College of Chemistry and Chemical Engineering, Nanjing University of Technology, Nanjing 210009, P. R. China

\section{Supporting Information:}

\section{Determination soap concentrations in the biodiesel}

It was believed that the saponification of oil and $\mathrm{KOH}$ was unavoidable in alkali-catalyzed transesterification, so we determinated the soap concentrations in our experiments. Soap concentrations were measured by AOCS method Cc 17-19 with small modification. The titration procedure as follows:

1. Dissolve sample in $100 \mathrm{ml}$ of acetone containing 2 percent distilled water.

2. Add $2 \mathrm{ml}$ of $1 \%$ phenolphthalein indicator in isopropyl alcohol

3. Titrate with $0.1 \mathrm{~mol} / \mathrm{l} \mathrm{HCl}$ until the red color of phenolphthalein disappears. This indicates the neutralization of the free catalyst in the sample.

4. Add $1 \mathrm{ml}$ of bromophenol blue indicator $(0.4 \%$ in water $)$ until the bromophenol blue changes from blue to yellow. This indicates that all of the soap should have been split into FFA and salt. Designate this quantity of solution as "A", do the following calculation: $\frac{A \times 0.1 \times 320.56}{1000 \times W}=$ grams of soap (as potassium oleate)/gram of sample

\section{Two-level-four- factor experimental design and the corresponding experimental} results

It was shown that the residence time, the reaction temperature, the $\mathrm{KOH}$ concentration, and the methanol to oil molar ratio had significant effects on yield of 
methyl ester. In order to determine which one exerted more effect on this reaction, a statistical analysis was conducted based on a two-level-four-factor experimental design. Table 1 shows the coded and corresponding uncoded values for optimization of transesterification conditions with cottonseed oil as raw materials. Table 2 shows the corresponding experimental design and the yield of methyl ester under different transesterification conditions.

Table 1. Independent variables and levels used for optimization of transesterification conditions

\begin{tabular}{cccc}
\hline Independent Symbols & Variables & \multicolumn{2}{c}{ Levels } \\
\cline { 3 - 4 } & & -1 & 1 \\
\hline Reaction temperature $\left({ }^{\circ} \mathrm{C}\right)$ & $\mathrm{X}_{1}$ & 30 & 60 \\
Methanol to oil molar ratio $(\mathrm{mol} / \mathrm{mol})$ & $\mathrm{X}_{2}$ & 3 & 6 \\
Residence time $(\mathrm{min})$ & $\mathrm{X}_{3}$ & 3.68 & 5.89 \\
Catalyst concentration $(\mathrm{wt} \%)$ & $\mathrm{X}_{4}$ & 0.4 & 1.0 \\
\hline
\end{tabular}

Table 2. Two-level-four-factor experimental design for optimization of transesterification conditions

\begin{tabular}{cccccc}
\hline Design point & \multicolumn{4}{c}{ Coded independent variable levels } & \\
\cline { 2 - 5 } & $\mathrm{X}_{1}$ & $\mathrm{X}_{2}$ & $\mathrm{X}_{3}$ & $\mathrm{X}_{4}$ & Yield \\
\hline 1 & 1 & 1 & -1 & 1 & 90.45 \\
2 & -1 & 1 & 1 & 1 & 96.16 \\
3 & -1 & -1 & -1 & 1 & 74.2 \\
4 & 1 & 1 & 1 & -1 & 86.54 \\
5 & 1 & -1 & -1 & -1 & 64.7 \\
6 & -1 & -1 & 1 & -1 & 67.5 \\
7 & 1 & -1 & 1 & 1 & 80.4 \\
8 & -1 & 1 & -1 & -1 & 64.2 \\
9 & 1 & 1 & -1 & -1 & 76.5 \\
10 & -1 & 1 & 1 & -1 & 71.4 \\
11 & 1 & 1 & 1 & 1 & 99.4 \\
12 & -1 & 1 & -1 & 1 & 88.5 \\
13 & 1 & -1 & -1 & 1 & 75.2 \\
14 & -1 & -1 & -1 & -1 & 55.8 \\
15 & -1 & -1 & 1 & 1 & 82.6 \\
16 & 1 & -1 & 1 & -1 & 68.5 \\
\hline
\end{tabular}

